\title{
A functional equation related to inner product spaces in non-Archimedean $\mathcal{L}$-random normed spaces
}

\author{
Javad Vahidi', Choonkil Park ${ }^{2 *}$ and Reza Saadati ${ }^{*}$
}

"Correspondence:

baak@hanyang.ac.kr;

rsaadati@eml.cc

'Department of Mathematics, Iran

University of Science and

Technology, Tehran, Iran

${ }^{2}$ Department of Mathematics, Research Institute for Natural

Sciences, Hanyang University, Seoul,

133-791, Korea

\begin{abstract}
In this paper, we prove the stability of a functional equation related to inner product spaces in non-Archimedean $\mathcal{L}$-random normed spaces.

MSC: Primary 46S10; 39B52; 47S10; 26E30; $12 J 25$

Keywords: non-Archimedean spaces; additive and quadratic functional equation; Hyers-Ulam stability; $\mathcal{L}$-random normed spaces
\end{abstract}

\section{Introduction}

One of the most interesting questions in the theory of functional analysis concerning the Ulam stability problem of functional equations is as follows: When is it true that a mapping satisfying a functional equation approximately must be close to an exact solution of the given functional equation?

The first stability problem concerning group homomorphisms was raised by Ulam [1] in 1940 and affirmatively solved by Hyers [2]. The result of Hyers was generalized by Aoki [3] for approximate additive mappings and by ThM Rassias [4] for approximate linear mappings by allowing the difference Cauchy equation $\left\|f\left(x_{1}+x_{2}\right)-f\left(x_{1}\right)-f\left(x_{2}\right)\right\|$ to be controlled by $\varepsilon\left(\left\|x_{1}\right\|^{p}+\left\|x_{2}\right\|^{p}\right)$. In 1994, a generalization of the ThM Rassias' theorem was obtained by Găvruta [5], who replaced $\varepsilon\left(\left\|x_{1}\right\|^{p}+\left\|x_{2}\right\|^{p}\right)$ by a general control function $\varphi\left(x_{1}, x_{2}\right)$.

Quadratic functional equations were used to characterize inner product spaces [6]. A square norm on an inner product space satisfies the parallelogram equality $\left\|x_{1}+x_{2}\right\|^{2}+$ $\left\|x_{1}-x_{2}\right\|^{2}=2\left(\left\|x_{1}\right\|^{2}+\left\|x_{1}\right\|^{2}\right)$. The functional equation

$$
f(x+y)+f(x-y)=2 f(x)+2 f(y)
$$

is related to a symmetric bi-additive mapping $[7,8]$. It is natural that this equation is called a quadratic functional equation, and every solution of the quadratic equation (1.1) is said to be a quadratic mapping.

It was shown by ThM Rassias [9] that the norm defined over a real vector space $X$ is induced by an inner product if and only if for a fixed integer $n \geq 2$

$$
\sum_{i=1}^{n}\left\|x_{i}-\frac{1}{n} \sum_{j=1}^{n} x_{j}\right\|^{2}=\sum_{i=1}^{n}\left\|x_{i}\right\|^{2}-n\left\|\frac{1}{n} \sum_{i=1}^{n} x_{i}\right\|^{2}
$$

for all $x_{1}, \ldots, x_{n} \in X$. 
Let $\mathbb{K}$ be a field. A non-Archimedean absolute value on $\mathbb{K}$ is a function $|\cdot|: \mathbb{K} \rightarrow \mathbb{R}$ such that for any $a, b \in \mathbb{K}$ we have

(i) $|a| \geq 0$ and equality holds if and only if $a=0$,

(ii) $|a b|=|a||b|$,

(iii) $|a+b| \leq \max \{|a|,|b|\}$.

The condition (iii) is called the strict triangle inequality. By (ii), we have $|1|=|-1|=1$. Thus, by induction, it follows from (iii) that $|n| \leq 1$ for each integer $n$. We always assume in addition that || is non-trivial, i.e., that there is an $a_{0} \in \mathbb{K}$ such that $\left|a_{0}\right| \neq 0,1$.

Let $X$ be a linear space over a scalar field $\mathbb{K}$ with a non-Archimedean non-trivial valuation $|\cdot|$. A function $\|\cdot\|: X \rightarrow \mathbb{R}$ is a non-Archimedean norm (valuation) if it satisfies the following conditions:

(NA1) $\|x\|=0$ if and only if $x=0$;

(NA2) $\|r x\|=|r|\|x\|$ for all $r \in \mathbb{K}$ and $x \in X$;

(NA3) the strong triangle inequality (ultra-metric); namely,

$$
\|x+y\| \leq \max \{\|x\|,\|y\|\} \quad(x, y \in X) .
$$

Then $(X,\|\cdot\|)$ is called a non-Archimedean space.

Thanks to the inequality

$$
\left\|x_{m}-x_{l}\right\| \leq \max \left\{\left\|x_{j+1}-x_{j}\right\|: l \leq J \leq m-1\right\} \quad(m>l)
$$

a sequence $\left\{x_{m}\right\}$ is Cauchy in $X$ if and only if $\left\{x_{m+1}-x_{m}\right\}$ converges to zero in a non-Archimedean space. By a complete non-Archimedean space, we mean a nonArchimedean space in which every Cauchy sequence is convergent.

In 1897, Hensel [10] introduced a normed space, which does not have the Archimedean property.

During the last three decades, the theory of non-Archimedean spaces has gained the interest of physicists for their research in particular in problems coming from quantum physics, p-adic strings, and superstrings [11]. Although many results in the classical normed space theory have a non-Archimedean counterpart, but their proofs are essentially different and require an entirely new kind of intuition [12-16].

The main objective of this paper is to prove the Hyers-Ulam stability of the following functional equation related to inner product spaces:

$$
\sum_{i=1}^{n} f\left(x_{i}-\frac{1}{n} \sum_{j=1}^{n} x_{j}\right)=\sum_{i=1}^{n} f\left(x_{i}\right)-n f\left(\frac{1}{n} \sum_{i=1}^{n} x_{i}\right)
$$

$(n \in \mathbb{N}, n \geq 2)$ in non-Archimedean normed spaces. Interesting new results concerning functional equations related to inner product spaces have recently been obtained by Najati and ThM Rassias [18] as well as for the fuzzy stability of a functional equation related to inner product spaces by Park [19] and Gordji and Khodaei [20]. During the last decades, several stability problems for various functional equations have been investigated by many mathematicians; [21-56]. 


\section{Preliminaries}

The theory of random normed spaces ( $\mathrm{RN}$-spaces) is important as a generalization of the deterministic result of linear normed spaces and also in the study of random operator equations. The $\mathrm{RN}$-spaces may also provide us the appropriate tools to study the geometry of nuclear physics and have important applications in quantum particle physics. The Hyers-Ulam stability of different functional equations in RN-spaces and fuzzy normed spaces has been recently studied by Alsina [57], Mirmostafaee, Mirzavaziri, and Moslehian [58, 59], Miheț and Radu [60], Miheț, Saadati, and Vaezpour [61, 62], Baktash et al. [63], Najati [64], and Saadati et al. [65].

Let $\mathcal{L}=\left(L, \geq_{L}\right)$ be a complete lattice, that is, a partially ordered set in which every nonempty subset admits supremum and infimum and $0_{\mathcal{L}}=\inf L, 1_{\mathcal{L}}=\sup L$. The space of latticetic random distribution functions, denoted by $\Delta_{L}^{+}$, is defined as the set of all mappings $F: \mathbb{R} \cup\{-\infty,+\infty\} \rightarrow L$ such that $F$ is left continuous, non-decreasing on $\mathbb{R}$ and $F(0)=0_{\mathcal{L}}$, $F(+\infty)=1_{\mathcal{L}}$.

The subspace $D_{L}^{+} \subseteq \Delta_{L}^{+}$is defined as $D_{L}^{+}=\left\{F \in \Delta_{L}^{+}: l^{-} F(+\infty)=1_{\mathcal{L}}\right\}$, where $l^{-} f(x)$ denotes the left limit of the function $f$ at the point $x$. The space $\Delta_{L}^{+}$is partially ordered by the usual point-wise ordering of functions, that is, $F \geq G$ if and only if $F(t) \geq_{L} G(t)$ for all $t$ in $\mathbb{R}$. The maximal element for $\Delta_{L}^{+}$in this order is the distribution function given by

$$
\varepsilon_{0}(t)= \begin{cases}0_{\mathcal{L}}, & \text { if } t \leq 0 \\ 1_{\mathcal{L}}, & \text { if } t>0\end{cases}
$$

Definition 2.1 [66] A triangular norm ( $t$-norm) on $L$ is a mapping $\mathcal{T}:(L)^{2} \rightarrow L$ satisfying the following conditions:

(1) $(\forall x \in L)\left(\mathcal{T}\left(x, 1_{\mathcal{L}}\right)=x\right)$ (: boundary condition);

(2) $\left(\forall(x, y) \in(L)^{2}\right)(\mathcal{T}(x, y)=\mathcal{T}(y, x))$ (: commutativity);

(3) $\left(\forall(x, y, z) \in(L)^{3}\right)(\mathcal{T}(x, \mathcal{T}(y, z))=\mathcal{T}(\mathcal{T}(x, y), z))$ (: associativity);

(4) $\left(\forall\left(x, x^{\prime}, y, y^{\prime}\right) \in(L)^{4}\right)\left(x \leq_{L} x^{\prime}\right.$ and $\left.y \leq_{L} y^{\prime} \Longrightarrow \mathcal{T}(x, y) \leq_{L} \mathcal{T}\left(x^{\prime}, y^{\prime}\right)\right)$ (: monotonicity).

Let $\left\{x_{n}\right\}$ be a sequence in $L$ converging to $x \in L$ (equipped the order topology). The $t$ norm $\mathcal{T}$ is called a continuous $t$-norm if

$$
\lim _{n \rightarrow \infty} \mathcal{T}\left(x_{n}, y\right)=\mathcal{T}(x, y)
$$

for any $y \in L$.

A $t$-norm $\mathcal{T}$ can be extended (by associativity) in a unique way to an $n$-array operation taking for $\left(x_{1}, \ldots, x_{n}\right) \in L^{n}$ the value $\mathcal{T}\left(x_{1}, \ldots, x_{n}\right)$ defined by

$$
\mathcal{T}_{i=1}^{0} x_{i}=1, \quad \mathcal{T}_{i=1}^{n} x_{i}=\mathcal{T}\left(\mathcal{T}_{i=1}^{n-1} x_{i}, x_{n}\right)=\mathcal{T}\left(x_{1}, \ldots, x_{n}\right) .
$$

The $t$-norm $\mathcal{T}$ can also be extended to a countable operation taking, for any sequence $\left\{x_{n}\right\}$ in $L$, the value

$$
\mathcal{T}_{i=1}^{\infty} x_{i}=\lim _{n \rightarrow \infty} \mathcal{T}_{i=1}^{n} x_{i}
$$

The limit on the right side of (2.1) exists since the sequence $\left(\mathcal{T}_{i=1}^{n} x_{i}\right)_{n \in \mathbb{N}}$ is non-increasing and bounded from below. 
Note that we put $\mathcal{T}=T$ whenever $L=[0,1]$. If $T$ is a $t$-norm then, for all $x \in[0,1]$ and $n \in N \cup\{0\}, x_{T}^{(n)}$ is defined by 1 if $n=0$ and $T\left(x_{T}^{(n-1)}, x\right)$ if $n \geq 1$. A $t$-norm $T$ is said to be of Hadžić-type (we denote by $T \in \mathcal{H}$ ) if the family $\left(x_{T}^{(n)}\right)_{n \in N}$ is equi-continuous at $x=1$ (see [67]).

Definition 2.2 [66] A continuous $t$-norm $\mathcal{T}$ on $L=[0,1]^{2}$ is said to be continuous $t$ representable if there exist a continuous $t$-norm $*$ and a continuous $t$-co-norm $\diamond$ on $[0,1]$ such that, for all $x=\left(x_{1}, x_{2}\right), y=\left(y_{1}, y_{2}\right) \in L$,

$$
\mathcal{T}(x, y)=\left(x_{1} * y_{1}, x_{2} \diamond y_{2}\right)
$$

For example,

$$
\mathcal{T}(a, b)=\left(a_{1} b_{1}, \min \left\{a_{2}+b_{2}, 1\right\}\right)
$$

and

$$
\mathbf{M}(a, b)=\left(\min \left\{a_{1}, b_{1}\right\}, \max \left\{a_{2}, b_{2}\right\}\right)
$$

for all $a=\left(a_{1}, a_{2}\right), b=\left(b_{1}, b_{2}\right) \in[0,1]^{2}$ are continuous $t$-representable.

Define the mapping $\mathcal{T}_{\wedge}$ from $L^{2}$ to $L$ by

$$
\mathcal{T}_{\wedge}(x, y)=\min (x, y)= \begin{cases}x, & \text { if } y \geq_{L} x, \\ y, & \text { if } x \geq_{L} y .\end{cases}
$$

Recall (see [67, 68]) that, if $\left\{x_{n}\right\}$ is a given sequence in $L$, then $\left(\mathcal{T}_{\wedge}\right)_{i=1}^{n} x_{i}$ is defined recurrently by $\left(\mathcal{T}_{\wedge}\right)_{i=1}^{1} x_{i}=x_{1}$ and $\left(\mathcal{T}_{\wedge}\right)_{i=1}^{n} x_{i}=\mathcal{T}_{\wedge}\left(\left(\mathcal{T}_{\wedge}\right)_{i=1}^{n-1} x_{i}, x_{n}\right)$ for all $n \geq 2$.

A negation on $\mathcal{L}$ is any decreasing mapping $\mathcal{N}: L \rightarrow L$ satisfying $\mathcal{N}\left(0_{\mathcal{L}}\right)=1_{\mathcal{L}}$ and $\mathcal{N}\left(1_{\mathcal{L}}\right)=0_{\mathcal{L}}$. If $\mathcal{N}(\mathcal{N}(x))=x$ for all $x \in L$, then $\mathcal{N}$ is called an involutive negation. In the following, $\mathcal{L}$ is endowed with a (fixed) negation $\mathcal{N}$.

Definition 2.3 A latticetic random normed space is a triple $\left(X, \mu, \mathcal{T}_{\wedge}\right)$, where $X$ is a vector space and $\mu$ is a mapping from $X$ into $D_{L}^{+}$satisfying the following conditions:

(LRN1) $\mu_{x}(t)=\varepsilon_{0}(t)$ for all $t>0$ if and only if $x=0$;

(LRN2) $\mu_{\alpha x}(t)=\mu_{x}\left(\frac{t}{|\alpha|}\right)$ for all $x$ in $X, \alpha \neq 0$ and $t \geq 0$;

(LRN3) $\mu_{x+y}(t+s) \geq_{L} \mathcal{T}_{\wedge}\left(\mu_{x}(t), \mu_{y}(s)\right)$ for all $x, y \in X$ and $t, s \geq 0$.

We note that, from (LPN2), it follows that $\mu_{-x}(t)=\mu_{x}(t)$ for all $x \in X$ and $t \geq 0$.

Example 2.4 Let $L=[0,1] \times[0,1]$ and an operation $\leq_{L}$ be defined by

$$
\begin{aligned}
& L=\left\{\left(a_{1}, a_{2}\right):\left(a_{1}, a_{2}\right) \in[0,1] \times[0,1] \text { and } a_{1}+a_{2} \leq 1\right\} \\
& \left(a_{1}, a_{2}\right) \leq_{L}\left(b_{1}, b_{2}\right) \quad \Longleftrightarrow \quad a_{1} \leq b_{1}, \quad a_{2} \geq b_{2}, \quad \forall a=\left(a_{1}, a_{2}\right), b=\left(b_{1}, b_{2}\right) \in L .
\end{aligned}
$$

Then $\left(L, \leq_{L}\right)$ is a complete lattice (see [66]). In this complete lattice, we denote its units by $0_{L}=(0,1)$ and $1_{L}=(1,0)$. Let $(X,\|\cdot\|)$ be a normed space. Let $\mathcal{T}(a, b)=$ 
$\left(\min \left\{a_{1}, b_{1}\right\}, \max \left\{a_{2}, b_{2}\right\}\right)$ for all $a=\left(a_{1}, a_{2}\right), b=\left(b_{1}, b_{2}\right) \in[0,1] \times[0,1]$ and $\mu$ be a mapping defined by

$$
\mu_{x}(t)=\left(\frac{t}{t+\|x\|}, \frac{\|x\|}{t+\|x\|}\right), \quad \forall t \in \mathbb{R}^{+} .
$$

Then $(X, \mu, \mathcal{T})$ is a latticetic random normed space.

If $\left(X, \mu, \mathcal{T}_{\wedge}\right)$ is a latticetic random normed space, then we have

$$
\mathcal{V}=\left\{V(\varepsilon, \lambda): \varepsilon>_{L} 0_{\mathcal{L}}, \lambda \in L \backslash\left\{0_{\mathcal{L}}, 1_{\mathcal{L}}\right\}\right\}
$$

is a complete system of neighborhoods of null vector for a linear topology on $X$ generated by the norm $F$, where

$$
V(\varepsilon, \lambda)=\left\{x \in X: F_{x}(\varepsilon)>_{L} \mathcal{N}(\lambda)\right\}
$$

Definition 2.5 Let $\left(X, \mu, \mathcal{T}_{\wedge}\right)$ be a latticetic random normed space.

(1) A sequence $\left\{x_{n}\right\}$ in $X$ is said to be convergent to a point $x \in X$ if, for any $t>0$ and $\varepsilon \in L \backslash\left\{0_{\mathcal{L}}\right\}$, there exists a positive integer $N$ such that $\mu_{x_{n}-x}(t)>_{L} \mathcal{N}(\varepsilon)$ for all $n \geq N$.

(2) A sequence $\left\{x_{n}\right\}$ in $X$ is called a Cauchy sequence if, for any $t>0$ and $\varepsilon \in L \backslash\left\{0_{\mathcal{L}}\right\}$, there exists a positive integer $N$ such that $\mu_{x_{n}-x_{m}}(t)>{ }_{L} \mathcal{N}(\varepsilon)$ for all $n \geq m \geq N$.

(3) A latticetic random normed space $\left(X, \mu, \mathcal{T}_{\wedge}\right)$ is said to be complete if every Cauchy sequence in $X$ is convergent to a point in $X$.

Theorem 2.6 If $\left(X, \mu, \mathcal{T}_{\wedge}\right)$ is a latticetic random normed space and $\left\{x_{n}\right\}$ is a sequence such that $x_{n} \rightarrow x$, then $\lim _{n \rightarrow \infty} \mu_{x_{n}}(t)=\mu_{x}(t)$.

Proof The proof is the same as in classical random normed spaces (see [17]).

Lemma 2.7 Let $\left(X, \mu, \mathcal{T}_{\wedge}\right)$ be a latticetic random normed space and $x \in X$. If

$$
\mu_{x}(t)=C, \quad \forall t>0,
$$

then $C=1_{\mathcal{L}}$ and $x=0$.

Proof Let $\mu_{x}(t)=C$ for all $t>0$. Since $\operatorname{Ran}(\mu) \subseteq D_{L}^{+}$, we have $C=1_{\mathcal{L}}$ and, by (LRN1), we conclude that $x=0$.

\section{Hyers-Ulam stability in non-Archimedean latticetic random spaces}

In the rest of this paper, unless otherwise explicitly stated, we will assume that $G$ is an additive group and that $X$ is a complete non-Archimedean latticetic random space. For convenience, we use the following abbreviation for a given mapping $f: G \rightarrow X$ :

$$
\Delta f\left(x_{1}, \ldots, x_{n}\right)=\sum_{i=1}^{n} f\left(x_{i}-\frac{1}{n} \sum_{j=1}^{n} x_{j}\right)-\sum_{i=1}^{n} f\left(x_{i}\right)+n f\left(\frac{1}{n} \sum_{i=1}^{n} x_{i}\right)
$$

for all $x_{1}, \ldots, x_{n} \in G$, where $n \geq 2$ is a fixed integer. 
Lemma 3.1 [18] Let $V_{1}$ and $V_{2}$ be real vector spaces. If an odd mappingf $: V_{1} \rightarrow V_{2}$ satisfies the functional equation (1.2), then $f$ is additive.

Let $\mathcal{K}$ be a non-Archimedean field, $\mathcal{X}$ a vector space over $\mathcal{K}$ and $\left(\mathcal{Y}, \mu, \mathcal{T}_{\wedge}\right)$ a nonArchimedean complete $L R N$-space over $\mathcal{K}$. In the following theorem, we prove the HyersUlam stability of the functional equation (1.2) in non-Archimedean latticetic random spaces for an odd mapping case.

Theorem 3.2 Let $\mathcal{K}$ be a non-Archimedean field and $\left(\mathcal{X}, \mu, \mathcal{T}_{\wedge}\right)$ a non-Archimedean complete LRN-space over $\mathcal{K}$. Let $\varphi: G^{n} \rightarrow D_{L}^{+}$be a distribution function such that

$$
\lim _{m \rightarrow \infty} \varphi_{2^{m} x_{1}, 2^{m} x_{2}, \ldots, 2^{m} x_{n}}\left(|2|^{m} t\right)=1_{\mathcal{L}}=\lim _{m \rightarrow \infty} \Phi_{2^{m-1} x}\left(|2|^{m} t\right)
$$

for all $x, x_{1}, x_{2}, \ldots, x_{n} \in G$, and

$$
\tilde{\varphi}_{x}(t)=\lim _{m \rightarrow \infty} \min \left\{\Phi_{2^{k} x}\left(|2|^{k} t\right): 0 \leq k<m\right\}
$$

exists for all $x \in G$, where

$$
\Phi_{x}(t):=\min \left\{\varphi_{2 x, 0, \ldots, 0}(t), \min \left\{\varphi_{x, x, 0, \ldots, 0}\left(\frac{|2| t}{n}\right), \varphi_{x,-x, \ldots,-x}(|2| t), \varphi(-x, x, \ldots, x)\right\}\right\}
$$

for all $x \in G$. Suppose that an odd mapping $f: G \rightarrow X$ satisfies the inequality

$$
\mu_{\Delta f\left(x_{1}, \ldots, x_{n}\right)}(t) \geq_{L} \varphi_{x_{1}, x_{2}, \ldots, x_{n}}(t)
$$

for all $x_{1}, x_{2}, \ldots, x_{n} \in G$ and $t>0$. Then there exists an additive mapping $A: G \rightarrow X$ such that

$$
\mu_{f(x)-A(x)}(t) \geq_{L} \tilde{\varphi}_{x}(|2| t)
$$

for all $x \in G$ and $t>0$, and if

$$
\lim _{\ell \rightarrow \infty} \lim _{m \rightarrow \infty} \min \left\{\Phi_{2^{k} x}\left(|2|^{k} t\right): \ell \leq k<m+\ell\right\}=1_{\mathcal{L}}
$$

then $A$ is a unique additive mapping satisfying (3.5).

Proof Letting $x_{1}=n x_{1}, x_{i}=n x_{1}^{\prime}(i=2, \ldots, n)$ in (3.4) and using the oddness of $f$, we obtain that

$$
\mu_{n f\left(x_{1}+(n-1) x_{1}^{\prime}\right)+f\left((n-1)\left(x_{1}-x_{1}^{\prime}\right)\right)-(n-1) f\left(x_{1}-x_{1}^{\prime}\right)-f\left(n x_{1}\right)-(n-1) f\left(n x_{1}^{\prime}\right)}(t) \geq_{L} \varphi_{n x_{1}, n x_{1}^{\prime}, \ldots, n x_{1}^{\prime}}(t)
$$

for all $x_{1}, x_{1}^{\prime} \in G$ and $t>0$. Interchanging $x_{1}$ with $x_{1}^{\prime}$ in (3.7) and using the oddness of $f$, we get

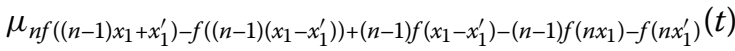

$$
\begin{aligned}
& \geq_{L} \varphi_{n x_{1}^{\prime}, n x_{1}, \ldots, n x_{1}}(t)
\end{aligned}
$$


for all $x_{1}, x_{1}^{\prime} \in G$ and $t>0$. It follows from (3.7) and (3.8) that

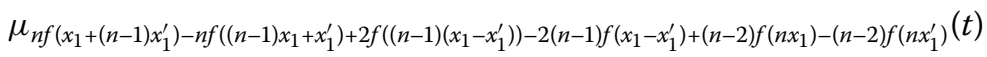

$$
\begin{aligned}
& \geq_{L} \min \left\{\varphi_{n x_{1}, n x_{1}^{\prime}, \ldots, n x_{1}^{\prime}}(t), \varphi_{n x_{1}^{\prime}, n x_{1}, \ldots, n x_{1}}(t)\right\}
\end{aligned}
$$

for all $x_{1}, x_{1}^{\prime} \in G$ and $t>0$. Setting $x_{1}=n x_{1}, x_{2}=-n x_{1}^{\prime}, x_{i}=0(i=3, \ldots, n)$ in (3.4) and using the oddness of $f$, we get

$$
\begin{aligned}
& \mu_{f\left((n-1) x_{1}+x_{1}^{\prime}\right)-f\left(x_{1}+(n-1) x_{1}^{\prime}\right)+2 f\left(x_{1}-x_{1}^{\prime}\right)-f\left(n x_{1}\right)+f\left(n x_{1}^{\prime}\right)}(t) \\
& \quad \geq_{L} \varphi_{n x_{1},-n x_{1}^{\prime}, 0, \ldots, 0}(t)
\end{aligned}
$$

for all $x_{1}, x_{1}^{\prime} \in G$ and $t>0$. It follows from (3.9) and (3.10) that

$$
\begin{aligned}
& \mu_{f\left((n-1)\left(x_{1}-x_{1}^{\prime}\right)\right)+f\left(x_{1}-x_{1}^{\prime}\right)-f\left(n x_{1}\right)+f\left(n x_{1}^{\prime}\right)}(t) \\
& \quad \geq_{L} \min \left\{\varphi_{n x_{1},-n x_{1}^{\prime}, 0, \ldots, 0}\left(\frac{|2|}{n}\right), \varphi_{n x_{1}, n x_{1}^{\prime}, \ldots, n x_{1}^{\prime}}\left(\frac{|2|}{n}\right), \varphi_{n x_{1}^{\prime}, n x_{1}, \ldots, n x_{1}}\left(\frac{|2|}{n}\right)\right\}
\end{aligned}
$$

for all $x_{1}, x_{1}^{\prime} \in G$ and $t>0$. Putting $x_{1}=n\left(x_{1}-x_{1}^{\prime}\right), x_{i}=0(i=2, \ldots, n)$ in (3.4), we obtain

$$
\mu_{f\left(n\left(x_{1}-x_{1}^{\prime}\right)\right)-f\left((n-1)\left(x_{1}-x_{1}^{\prime}\right)\right)-f\left(\left(x_{1}-x_{1}^{\prime}\right)\right)}(t) \geq_{L} \varphi_{n\left(x_{1}-x_{1}^{\prime}\right), 0, \ldots, 0}(t)
$$

for all $x_{1}, x_{1}^{\prime} \in G$ and $t>0$. It follows from (3.11) and (3.12) that

$$
\begin{aligned}
\mu_{f\left(n\left(x_{1}-x_{1}^{\prime}\right)\right)-f\left(n x_{1}\right)+f\left(n x_{1}^{\prime}\right)}(t) \geq_{L} & \min \left\{\varphi_{n\left(x_{1}-x_{1}^{\prime}\right), 0, \ldots, 0}(t), \varphi_{n x_{1},-n x_{1}^{\prime}, 0, \ldots, 0}\left(\frac{|2|}{n} t\right),\right. \\
& \left.\min \left\{\varphi_{n x_{1}, n x_{1}^{\prime}, \ldots, n x_{1}^{\prime}}\left(\frac{|2|}{n} t\right), \varphi_{n x_{1}^{\prime}, n x_{1}, \ldots, n x_{1}}\left(\frac{|2|}{n} t\right)\right\}\right\}
\end{aligned}
$$

for all $x_{1}, x_{1}^{\prime} \in G$ and $t>0$. Replacing $x_{1}$ and $x_{1}^{\prime}$ by $\frac{x}{n}$ and $\frac{-x}{n}$ in (3.13), respectively, we obtain

$$
\mu_{f(2 x)-2 f(x)}(t) \geq_{L} \min \left\{\varphi_{2 x, 0, \ldots, 0}(t), \min \left\{\varphi_{x, x, 0, \ldots, 0}\left(\frac{|2|}{n} t\right), \varphi_{x,-x, \ldots,-x}(t), \varphi_{-x, x, \ldots, x}(t)\right\}\right\}
$$

for all $x \in G$ and $t>0$. Hence,

$$
\mu_{\frac{f(2 x)}{2}-f(x)}(t) \geq_{L} \Phi_{x}(|2| t)
$$

for all $x \in G$ and $t>0$. Replacing $x$ by $2^{m-1} x$ in (3.14), we have

$$
\mu_{\frac{f\left(2^{m-1} x\right)}{2^{m-1}}-\frac{f\left(2^{m} m_{x}\right)}{2^{m}}}(t) \geq_{L} \Phi_{2^{m-1} x}\left(|2|^{m} t\right)
$$

for all $x \in G$ and $t>0$. It follows from (3.1) and (3.15) that the sequence $\left\{\frac{f\left(2^{m} x\right)}{2^{m}}\right\}$ is Cauchy. Since $X$ is complete, we conclude that $\left\{\frac{f\left(2^{m} x\right)}{2^{m}}\right\}$ is convergent. So one can define the mapping $A: G \rightarrow X$ by $A(x):=\lim _{m \rightarrow \infty} \frac{f\left(2^{m} x\right)}{2^{m}}$ for all $x \in G$. It follows from (3.14) and (3.15) that

$$
\mu_{f(x)-\frac{f\left(2^{m} x\right)}{2^{m}}}(t) \geq_{L} \min \left\{\Phi_{2^{k} x}\left(|2|^{k+1} t\right): 0 \leq k<m\right\}
$$


for all $m \in \mathbb{N}$ and all $x \in G$ and $t>0$. By taking $m$ to approach infinity in (3.16) and using (3.2), one gets (3.5). By (3.1) and (3.4), we obtain

$$
\begin{aligned}
\mu_{\Delta A\left(x_{1}, x_{2}, \ldots, x_{n}\right)}(t) & =\lim _{m \rightarrow \infty} \mu_{\Delta f\left(2^{m} x_{1}, 2^{m} x_{2}, \ldots, 2^{m} x_{n}\right)}\left(|2|^{m} t\right) \\
& \geq_{L} \lim _{m \rightarrow \infty} \varphi_{2^{m} x_{1}, 2^{m} x_{2}, \ldots, 2^{m} x_{n}}\left(|2|^{m} t\right)=1_{\mathcal{L}}
\end{aligned}
$$

for all $x_{1}, x_{2}, \ldots, x_{n} \in G$ and $t>0$. Thus the mapping $A$ satisfies (1.2). By Lemma 3.1, $A$ is additive.

If $A^{\prime}$ is another additive mapping satisfying (3.5), then

$$
\begin{aligned}
\mu_{A(x)-A^{\prime}(x)}(t) & =\lim _{\ell \rightarrow \infty} \mu_{A\left(2^{\ell} x\right)-A^{\prime}\left(2^{\ell} x\right)}\left(|2|^{\ell} t\right) \\
& \geq_{L} \lim _{\ell \rightarrow \infty} \min \left\{\mu_{A\left(2^{\ell} x\right)-f\left(2^{\ell} x\right)}\left(|2|^{\ell} t\right), \mu_{f\left(2^{\ell} x\right)-Q^{\prime}\left(2^{\ell} x\right)}\left(|2|^{\ell} t\right)\right\} \\
& \geq_{L} \lim _{\ell \rightarrow \infty} \lim _{m \rightarrow \infty} \min \left\{\tilde{\varphi}_{2^{k} x}\left(|2|^{k+1}\right): \ell \leq k<m+\ell\right\}=0
\end{aligned}
$$

for all $x \in G$, thus, $A=A^{\prime}$.

Corollary 3.3 Let $\rho:[0, \infty) \rightarrow[0, \infty)$ be a function satisfying

(i) $\rho(|2| t) \leq \rho(|2|) \rho(t)$ for all $t \geq 0$,

(ii) $\rho(|2|)<|2|$.

Let $\varepsilon>0$ and let $\left(G, \mu, \mathcal{T}_{\wedge}\right)$ be an LRN-space in which $L=D^{+}$. Suppose that an odd mapping $: G \rightarrow X$ satisfies the inequality

$$
\mu_{\Delta f\left(x_{1}, \ldots, x_{n}\right)}(t) \geq_{L} \frac{t}{t+\varepsilon \sum_{i=1}^{n} \rho\left(\left\|x_{i}\right\|\right)}
$$

for all $x_{1}, \ldots, x_{n} \in G$ and $t>0$. Then there exists a unique additive mapping $A: G \rightarrow X$ such that

$$
\mu_{f(x)-A(x)}(t) \geq_{L} \frac{t}{t+\frac{2 n}{|2|^{2}} \varepsilon \rho(\|x\|)}
$$

for all $x \in G$ and $t>0$.

Proof Defining $\varphi: G^{n} \rightarrow D^{+}$by $\varphi_{x_{1}, \ldots, x_{n}}(t):=\frac{t}{t+\varepsilon \sum_{i=1}^{n} \rho\left(\left\|x_{i}\right\|\right)}$, we have

$$
\lim _{m \rightarrow \infty} \varphi_{2^{m} x_{1}, \ldots, 2^{m} x_{n}}\left(|2|^{m} t\right) \geq_{L} \lim _{m \rightarrow \infty} \varphi_{x_{1}, \ldots, x_{n}}\left(\left(\frac{|2|}{\rho(|2|)}\right)^{m}\right)=1_{\mathcal{L}}
$$

for all $x_{1}, \ldots, x_{n} \in G$ and $t>0$. So, we have

$$
\tilde{\varphi}_{x}(t):=\lim _{m \rightarrow \infty} \min \left\{\Phi_{2^{k}}\left(|2|^{k}\right): 0 \leq k<m\right\}=\Phi_{x}(t)
$$

and

$$
\lim _{\ell \rightarrow \infty} \lim _{m \rightarrow \infty} \min \left\{\Phi_{2^{k} x}\left(|2|^{k}\right): \ell \leq k<m+\ell\right\}=\lim _{\ell \rightarrow \infty} \Phi_{2^{\ell}}\left(|2|^{\ell}\right)=1_{\mathcal{L}}
$$


for all $x \in G$ and $t>0$. It follows from (3.3) that

$$
\Phi_{x}(t)=\min \left\{\frac{t}{t+\varepsilon \rho(\|2 x\|)}, \frac{t}{t+\frac{1}{|2|} 2 n \varepsilon \rho(\|x\|)}\right\}=\frac{|2| t}{|2| t+2 n \varepsilon \rho(\|x\|)} .
$$

Applying Theorem 3.2, we conclude that

$$
\mu_{f(x)-A(x)}(t) \geq_{L} \tilde{\varphi}_{x}(|2| t)=\Phi_{x}(|2| t)=\frac{t}{t+\frac{2 n}{|2|^{2}} \varepsilon \rho(\|x\|)}
$$

for all $x \in G$ and $t>0$.

Lemma 3.4 [18] Let $V_{1}$ and $V_{2}$ be real vector spaces. If an even mapping $f: V_{1} \rightarrow V_{2}$ satisfies the functional equation (1.2), then $f$ is quadratic.

In the following theorem, we prove the Hyers-Ulam stability of the functional equation (1.2) in non-Archimedean LRN-spaces for an even mapping case.

Theorem 3.5 Let $\varphi: G^{n} \rightarrow D_{L}^{+}$be a function such that

$$
\lim _{m \rightarrow \infty} \varphi_{2^{m} x_{1}, 2^{m} x_{2}, \ldots, 2^{m} x_{n}}\left(|2|^{2 m} t\right)=1_{\mathcal{L}}=\lim _{m \rightarrow \infty} \tilde{\varphi}_{2^{m-1} x}\left(|2|^{2 m} t\right)
$$

for all $x, x_{1}, x_{2}, \ldots, x_{n} \in G, t>0$ and

$$
\tilde{\varphi}_{x}^{\prime}(t)=\lim _{m \rightarrow \infty} \min \left\{\tilde{\varphi}_{{ }^{k} x}\left(|2|^{2 k} t\right): 0 \leq k<m\right\}
$$

exists for all $x \in G$ and $t>0$ where

$$
\begin{aligned}
\tilde{\varphi}_{x}^{\prime}(t):= & \min \left\{\varphi_{n x, n x, 0, \ldots, 0}(|2 n-2| t), \varphi_{n x, 0, \ldots, 0}(|n-1| t),\right. \\
& \left.\varphi_{x,(n-1) x, 0, \ldots, 0,0}(|n-1| t), \Psi_{x}(|n-1| t)\right\}
\end{aligned}
$$

and

$$
\Psi_{x}(t):=\min \left\{n \varphi_{n x, 0, \ldots, 0}\left(\frac{|2|}{n} t\right), \varphi_{n x, 0, \ldots, 0}(|2| t), \varphi_{0, n x, \ldots, n x}(|2| t)\right\}
$$

for all $x \in G$ and $t>0$. Suppose that an even mapping $f: G \rightarrow X$ with $f(0)=0$ satisfies the inequality (3.4) for all $x_{1}, x_{2}, \ldots, x_{n} \in G$ and $t>0$. Then there exists a quadratic mapping $Q: G \rightarrow X$ such that

$$
\mu_{f(x)-Q(x)}(t) \geq_{L} \tilde{\varphi}_{x}^{\prime}\left(|2|^{2} t\right)
$$

for all $x \in G, t>0$ and if

$$
\lim _{\ell \rightarrow \infty} \lim _{\ell \rightarrow \infty} \min \left\{\tilde{\varphi}_{2^{k} x}^{\prime}\left(|2|^{2 k} t\right): \ell \leq k<m+\ell\right\}=1_{\mathcal{L}}
$$

then $Q$ is a unique quadratic mapping satisfying (3.21). 
Proof Replacing $x_{1}$ by $n x_{1}$, and $x_{i}$ by $n x_{2}(i=2, \ldots, n)$ in (3.4) and using the evenness of $f$, we obtain

$$
\begin{aligned}
& \mu_{n f\left(x_{1}+(n-1) x_{2}\right)+f\left((n-1)\left(x_{1}-x_{2}\right)\right)+(n-1) f\left(x_{1}-x_{2}\right)-f\left(n x_{1}\right)-(n-1) f\left(n x_{2}\right)}(t) \\
& \quad \geq_{L} \varphi_{n x_{1}, n x_{2}, \ldots, n x_{2}}(t)
\end{aligned}
$$

for all $x_{1}, x_{2} \in G$ and $t>0$. Interchanging $x_{1}$ with $x_{2}$ in (3.23) and using the evenness of $f$, we obtain

$$
\begin{aligned}
& \mu_{n f\left((n-1) x_{1}+x_{2}\right)+f\left((n-1)\left(x_{1}-x_{2}\right)\right)+(n-1) f\left(x_{1}-x_{2}\right)-(n-1) f\left(n x_{1}\right)-f\left(n x_{2}\right)}(t) \\
& \quad \geq_{L} \varphi_{n x_{2}, n x_{1}, \ldots, n x_{1}}(t)
\end{aligned}
$$

for all $x_{1}, x_{2} \in G$ and $t>0$. It follows from (3.23) and (3.24) that

$$
\begin{aligned}
& \mu_{n f\left((n-1) x_{1}+x_{2}\right)+n f\left(x_{1}+(n-1) x_{2}\right)+2 f\left((n-1)\left(x_{1}-x_{2}\right)\right)+2(n-1) f\left(x_{1}-x_{2}\right)-n f\left(n x_{1}\right)-n f\left(n x_{2}\right)}(t) \\
& \quad \geq_{L} \min \left\{\varphi_{n x_{1}, n x_{2}, \ldots, n x_{2}}(t), \varphi_{n x_{2}, n x_{1}, \ldots, n x_{1}}(t)\right\}
\end{aligned}
$$

for all $x_{1}, x_{2} \in G$ and $t>0$. Setting $x_{1}=n x_{1}, x_{2}=-n x_{2}, x_{i}=0(i=3, \ldots, n)$ in (3.4) and using the evenness of $f$, we obtain

$$
\begin{aligned}
& \mu_{f\left((n-1) x_{1}+x_{2}\right)+f\left(x_{1}+(n-1) x_{2}\right)+2(n-1) f\left(x_{1}-x_{2}\right)-f\left(n x_{1}\right)-f\left(n x_{2}\right)}(t) \\
& \quad \geq_{L} \varphi_{n x_{1},-n x_{2}, 0, \ldots, 0}(t)
\end{aligned}
$$

for all $x_{1}, x_{2} \in G$ and $t>0$. So, it follows from (3.25) and (3.26) that

$$
\begin{aligned}
& \mu_{f\left((n-1)\left(x_{1}-x_{2}\right)\right)-(n-1)^{2} f\left(x_{1}-x_{2}\right)}(t) \\
& \quad \geq_{L} \min \left\{\varphi_{n x_{1},-n x_{2}, 0, \ldots, 0}\left(\frac{|2|}{n}\right), \varphi_{n x_{1}, n x_{2}, \ldots, n x_{2}}(|2| t), \varphi_{n x_{2}, n x_{1}, \ldots, n x_{1}}(|2| t)\right\}
\end{aligned}
$$

for all $x_{1}, x_{2} \in G$ and $t>0$. Setting $x_{1}=x, x_{2}=0$ in (3.27), we obtain

$$
\begin{aligned}
& \mu_{f((n-1) x)-(n-1)^{2} f(x)}(t) \\
& \quad \geq_{L} \min \left\{\varphi_{n x, 0, \ldots, 0}\left(\frac{|2|}{n} t\right), \varphi_{n x, 0, \ldots, 0}(|2| t), \varphi_{0, n x, \ldots, n x}(|2| t)\right\}
\end{aligned}
$$

for all $x \in G$ and $t>0$. Putting $x_{1}=n x, x_{i}=0(i=2, \ldots, n)$ in (3.4), one obtains

$$
\mu_{f(n x)-f((n-1) x)-(2 n-1) f(x)}(t) \geq_{L} \varphi_{n x, 0, \ldots, 0}(t)
$$

for all $x \in G$ and $t>0$. It follows from (3.28) and (3.29) that

$$
\begin{array}{r}
\mu_{f(n x)-n^{2} f(x)}(t) \geq_{L} \min \left\{\varphi_{n x, 0, \ldots, 0}(t), \varphi_{n x, 0, \ldots, 0}\left(\frac{|2|}{n} t\right),\right. \\
\left.\varphi_{n x, 0, \ldots, 0}(|2| t), \varphi_{0, n x, \ldots, n x}(|2| t)\right\}
\end{array}
$$


for all $x \in G$ and $t>0$. Letting $x_{2}=-(n-1) x_{1}$ and replacing $x_{1}$ by $\frac{x}{n}$ in (3.26), we get

$$
\mu_{f((n-1) x)-f((n-2) x)-(2 n-3) f(x)}(t) \geq_{L} \varphi_{x,(n-1) x, 0, \ldots, 0}(t)
$$

for all $x \in G$ and $t>0$. It follows from (3.28) and (3.31) that

$$
\begin{gathered}
\mu_{f((n-2) x)-(n-2)^{2} f(x)}(t) \geq_{L} \min \left\{\varphi_{x,(n-1) x, 0, \ldots, 0}(t), \varphi_{n x, 0, \ldots, 0}\left(\frac{|2|}{n} t\right),\right. \\
\left.\varphi_{n x, 0, \ldots, 0}(|2| t), \varphi_{0, n x, \ldots, n x}(|2| t)\right\}
\end{gathered}
$$

for all $x \in G$ and $t>0$. It follows from (3.30) and (3.32) that

$$
\mu_{f(n x)-f((n-2) x)-4(n-1) f(x)}(t) \geq_{L} \min \left\{\varphi_{n x, 0, \ldots, 0}(t), \varphi_{x,(n-1) x, 0, \ldots, 0}(t), \Psi_{x}(t)\right\}
$$

for all $x \in G$ and $t>0$. Setting $x_{1}=x_{2}=n x, x_{i}=0(i=3, \ldots, n)$ in (3.4), we obtain

$$
\mu_{f((n-2) x)+(n-1) f(2 x)-f(n x)}(t) \geq_{L} \varphi_{n x, n x, 0, \ldots, 0}(|2| t)
$$

for all $x \in G$ and $t>0$. It follows from (3.33) and (3.34) that

$$
\begin{aligned}
& \mu_{f(2 x)-4 f(x)}(t) \\
& \geq_{L} \min \left\{\varphi_{n x, n x, 0, \ldots, 0}(|2 n-2| t), \varphi_{n x, 0, \ldots, 0}(|n-1| t),\right. \\
& \left.\varphi_{x,(n-1) x, 0, \ldots, 0}(|n-1| t), \Psi_{x}(|n-1| t)\right\}
\end{aligned}
$$

for all $x \in G$ and $t>0$. Thus,

$$
\mu_{f(x)-\frac{f(2 x)}{2^{2}}}(t) \geq_{L} \tilde{\varphi}_{x}^{\prime}\left(|2|^{2} t\right)
$$

for all $x \in G$ and $t>0$. Replacing $x$ by $2^{m-1} x$ in (3.36), we have

$$
\mu_{\frac{f\left(2^{m-1} x\right)}{2^{2(m-1)}}-\frac{f\left(2^{m} x\right)}{2^{2 m}}}(t) \geq_{L} \tilde{\varphi}_{2^{m-1} x}\left(|2|^{2 m} t\right)
$$

for all $x \in G$ and $t>0$. It follows from (3.17) and (3.37) that the sequence $\left\{\frac{f\left(2^{m} x\right)}{2^{2 m}}\right\}$ is Cauchy. Since $X$ is complete, we conclude that $\left\{\frac{f\left(2^{m} x\right)}{2^{2 m}}\right\}$ is convergent. So, one can define the mapping $Q: G \rightarrow X$ by $Q(x):=\lim _{m \rightarrow \infty} \frac{f\left(2^{m} x\right)}{2^{2 m}}$ for all $x \in G$. By using induction, it follows from (3.36) and (3.37) that

$$
\mu_{f(x)-\frac{f\left(2^{\left.m_{x}\right)}\right.}{2^{2 m}}}(t) \geq_{L} \min \left\{\tilde{\varphi}_{2^{k} x}\left(|2|^{2 k+2} t\right): 0 \leq k<m\right\}
$$

for all $n \in \mathbb{N}$ and all $x \in G$ and $t>0$. By taking $m$ to approach infinity in (3.38) and using (3.18), one gets (3.21).

The rest of proof is similar to the proof of Theorem 3.2. 
Corollary 3.6 Let $\eta:[0, \infty) \rightarrow[0, \infty)$ be a function satisfying

(i) $\eta(|l| t) \leq \eta(|l|) \eta(t)$ for all $t \geq 0$,

(ii) $\eta(|l|)<|l|^{2}$ for $l \in\{2, n-1, n\}$.

Let $\varepsilon>0$ and let $\left(G, \mu, \mathcal{T}_{\wedge}\right)$ be a $\mathrm{LRN}$-space in which $L=D^{+}$. Suppose that an even mapping $f: G \rightarrow X$ with $f(0)=0$ satisfies the inequality

$$
\mu_{\Delta f\left(x_{1}, \ldots, x_{n}\right)}(t) \geq \frac{t}{t+\varepsilon \sum_{i=1}^{n} \eta\left(\left\|x_{i}\right\|\right)}
$$

for all $x_{1}, \ldots, x_{n} \in G$ and $t>0$. Then there exists a unique quadratic mapping $Q: G \rightarrow X$ such that

$$
\mu_{f(x)-Q(x)}(t) \geq \begin{cases}\frac{t}{t+\frac{2}{|2|^{2}} \varepsilon \eta(\|x\|)}, & \text { if } n=2 ; \\ \frac{t}{t+\frac{n}{|2|^{3}|n-1|} \varepsilon \eta(\|n x\|)}, & \text { if } n>2,\end{cases}
$$

for all $x \in G$ and $t>0$.

Proof Defining $\varphi: G^{n} \rightarrow D^{+}$by $\varphi_{x_{1}, \ldots, x_{n}}(t):=\frac{t}{t+\varepsilon \sum_{i=1}^{n} \eta\left(\left\|x_{i}\right\|\right)}$, we have

$$
\lim _{m \rightarrow \infty} \varphi_{2^{m} x_{1}, \ldots, 2^{m} x_{n}}\left(|2|^{2 m} t\right) \geq \lim _{m \rightarrow \infty} \varphi_{x_{1}, \ldots, x_{n}}\left(\left(\frac{|2|^{2}}{\eta(|2|)}\right)^{m}\right)=1_{\mathcal{L}}
$$

for all $x_{1}, \ldots, x_{n} \in G$ and $t>0$. We have

$$
\tilde{\varphi}_{x}^{\prime}(t):=\lim _{m \rightarrow \infty} \min \left\{\tilde{\varphi}_{2^{k} x}\left(|2|^{2 k} t\right): 0 \leq k<m\right\}
$$

and

$$
\lim _{\ell \rightarrow \infty} \lim _{m \rightarrow \infty} \min \left\{\tilde{\varphi}_{{ }^{\prime}{ }_{x}}\left(|2|^{2 k} t\right): \ell \leq k<m+\ell\right\}=\lim _{\ell \rightarrow \infty} \tilde{\varphi}_{{ }^{\prime}{ }^{\prime}{ }_{x}}\left(|2|^{2 \ell} t\right)=0
$$

for all $x \in G$ and $t>0$. It follows from (3.20) that

$$
\begin{aligned}
\Psi_{x}(t) & =\min \left\{\frac{|2| t}{|2| t+2 n \varepsilon \eta(\|n x\|)}, \frac{|2| t}{|2| t+2 \varepsilon \eta(\|n x\|)}, \frac{|2| t}{|2| t+2(n-1) \varepsilon \eta(\|n x\|)}\right\} \\
& =\frac{|2| t}{|2| t+n \varepsilon \eta(\|n x\|)} .
\end{aligned}
$$

Hence, by using (3.19), we obtain

$$
\begin{aligned}
\tilde{\varphi}_{x}^{\prime}(t) & =\min \left\{\frac{|2 n-2| t}{|2 n-2| t+2 \varepsilon \eta(\|n x\|)}, \frac{|n-1| t}{|n-1| t+\varepsilon \eta(\|n x\|)},\right. \\
& = \begin{cases}\frac{\mid}{|2 n-2| t+n \varepsilon \eta(\|n x\|)}, & \left.\frac{|n-1| t}{|n-1| t+\varepsilon(\eta(\|x\|)+\eta(\|(n-1) x\|))}\right\} \\
\frac{|2||||n-1| t}{|2||n-1| t+n \varepsilon \eta(\|n x\|)}, & \text { if } n>2,\end{cases}
\end{aligned}
$$

for all $x \in G$ and $t>0$. Applying Theorem 3.5, we conclude the required result. 
Lemma 3.7 [18] Let $V_{1}$ and $V_{2}$ be real vector spaces. A mapping $f: V_{1} \rightarrow V_{2}$ satisfies (1.2) if and only if there exist a symmetric bi-additive mapping $B: V_{1} \times V_{1} \rightarrow V_{2}$ and an additive mapping $A: V_{1} \rightarrow V_{2}$ such that $f(x)=B(x, x)+A(x)$ for all $x \in V_{1}$.

Now, we are ready to prove the main theorem concerning the Hyers-Ulam stability problem for the functional equation (1.2) in non-Archimedean spaces.

Theorem 3.8 Let $\varphi: G^{n} \rightarrow D_{L}^{+}$be a function satisfying (3.1) for all $x, x_{1}, x_{2}, \ldots, x_{n} \in G$, and $\tilde{\varphi}_{x}(t)$ and $\tilde{\varphi}_{x}^{\prime}(t)$ exist for all $x \in G$ and $t>0$, where $\tilde{\varphi}_{x}(t)$ and $\tilde{\varphi}_{x}^{\prime}(t)$ are defined as in Theorems 3.2 and 3.5. Suppose that a mapping $f: G \rightarrow X$ with $f(0)=0$ satisfies the inequality (3.4) for all $x_{1}, x_{2}, \ldots, x_{n} \in G$. Then there exist an additive mapping $A: G \rightarrow X$ and a quadratic mapping $Q: G \rightarrow X$ such that

$$
\mu_{f(x)-A(x)-Q(x)}(t) \geq_{L} \min \left\{\tilde{\varphi}_{x}\left(|2|^{2} t\right), \tilde{\varphi}_{-x}\left(|2|^{2} t\right), \tilde{\varphi}_{x}^{\prime}(|2| t), \frac{1}{|2|} \tilde{\varphi}_{-x}^{\prime}(|2| t)\right\}
$$

for all $x \in G$ and $t>0$. If

$$
\begin{aligned}
& \lim _{\ell \rightarrow \infty} \lim _{m \rightarrow \infty} \min \left\{\varphi_{2^{k} x}\left(|2|^{k} t\right): \ell \leq k<m+\ell\right\} \\
& \quad=1_{\mathcal{L}}=\lim _{\ell \rightarrow \infty} \lim _{m \rightarrow \infty} \min \left\{\tilde{\varphi}^{\prime}{ }^{k}{ }^{k}\left(|2|^{2 k} t\right): \ell \leq k<m+\ell\right\}
\end{aligned}
$$

then $A$ is a unique additive mapping and $Q$ is a unique quadratic mapping satisfying (3.39).

Proof Let $f_{e}(x)=\frac{1}{2}(f(x)+f(-x))$ for all $x \in G$. Then

$$
\begin{aligned}
\left\|\Delta f_{e}\left(x_{1}, \ldots, x_{n}\right)\right\| & =\left\|\frac{1}{2}\left(\Delta f\left(x_{1}, \ldots, x_{n}\right)+\Delta f\left(-x_{1}, \ldots,-x_{n}\right)\right)\right\| \\
& \leq \frac{1}{|2|} \max \left\{\varphi\left(x_{1}, \ldots, x_{n}\right), \varphi\left(-x_{1}, \ldots,-x_{n}\right)\right\}
\end{aligned}
$$

for all $x_{1}, x_{2}, \ldots, x_{n} \in G$ and $t>0$. By Theorem 3.5, there exists a quadratic mapping $Q$ : $G \rightarrow X$ such that

$$
\mu_{f_{e}(x)-Q(x)}(t) \geq_{L} \min \left\{\tilde{\varphi}_{x}^{\prime}\left(|2|^{3} t\right), \tilde{\varphi}_{-x}^{\prime}\left(|2|^{3} t\right)\right\}
$$

for all $x \in G$ and $t>0$. Also, let $f_{o}(x)=\frac{1}{2}(f(x)-f(-x))$ for all $x \in G$. By Theorem 3.2, there exists an additive mapping $A: G \rightarrow X$ such that

$$
\mu_{f_{o}(x)-A(x)}(t) \geq_{L} \min \left\{\tilde{\varphi}_{x}\left(|2|^{2} t\right), \tilde{\varphi}_{-x}\left(|2|^{2} t\right)\right\}
$$

for all $x \in G$ and $t>0$. Hence (3.39) follows from (3.40) and (3.41).

The rest of proof is trivial.

Corollary 3.9 Let $\gamma:[0, \infty) \rightarrow[0, \infty)$ be a function satisfying

(i) $\gamma(|l| t) \leq \gamma(|l|) \gamma(t)$ for all $t \geq 0$,

(ii) $\gamma(|l|)<|l|^{2}$ for $l \in\{2, n-1, n\}$. 
Let $\varepsilon>0,\left(G, \mu, \mathcal{T}_{\wedge}\right)$ be an LRN-space in which $L=D^{+}$and let $f: G \rightarrow X$ satisfy

$$
\mu_{\Delta f\left(x_{1}, \ldots, x_{n}\right)}(t) \geq \frac{t}{t+\varepsilon \sum_{i=1}^{n} \gamma\left(\left\|x_{i}\right\|\right)}
$$

for all $x_{1}, \ldots, x_{n} \in G, t>0$ and $f(0)=0$. Then there exist a unique additive mapping $A$ : $G \rightarrow X$ and a unique quadratic mapping $Q: G \rightarrow X$ such that

$$
\mu_{f(x)-A(x)-Q(x)}(t) \geq \frac{|2|^{3} t}{|2|^{3} t+2 n \varepsilon \gamma(\|x\|)}
$$

for all $x \in G$ and $t>0$.

Proof The result follows from Corollaries 3.6 and 3.3.

\section{Competing interests}

The authors declare that they have no competing interests.

\section{Authors' contributions}

All authors carried out the proof. All authors conceived of the study, and participated in its design and coordination. All authors read and approved the final manuscript.

\section{Received: 6 April 2012 Accepted: 18 July 2012 Published: 31 July 2012}

\section{References}

1. Ulam, SM: A Collection of the Mathematical Problems. Interscience, New York (1960)

2. Hyers, DH: On the stability of the linear functional equation. Proc. Natl. Acad. Sci. USA 27, $222-224$ (1941)

3. Aoki, T: On the stability of the linear transformation in Banach spaces. J. Math. Soc. Jpn. 2, 64-66 (1950)

4. Rassias, ThM: On the stability of the linear mapping in Banach spaces. Proc. Am. Math. Soc. 72, 297-300 (1978)

5. Găvruta, P: A generalization of the Hyers-Ulam-Rassias stability of approximately additive mappings. J. Math. Anal. Appl. 184, 431-436 (1994)

6. Amir, D: Characterizations of Inner Product Spaces. Birkhäuser, Basel (1986)

7. Aczel, J, Dhombres, J: Functional Equations in Several Variables. Cambridge University Press, Cambridge (1989)

8. Kannappan, Pl: Quadratic functional equation and inner product spaces. Results Math. 27, 368-372 (1995)

9. Rassias, ThM: New characterization of inner product spaces. Bull. Sci. Math. 108, 95-99 (1984)

10. Hensel, K: Uber eine neue Begrundung der Theorie der algebraischen Zahlen. Jahresber. Dtsch. Math.-Ver. 6, 83-88 (1897)

11. Khrennikov, A: Non-Archimedean Analysis: Quantum Paradoxes, Dynamical Systems and Biological Models. Kluwer Academic, Dordrecht (1997)

12. Moslehian, MS, Rassias, ThM: Stability of functional equations in non-Archimedean spaces. Appl. Anal. Discrete Math. 1, 325-334 (2007)

13. Narici, L, Beckenstein, E: Strange terrain-non-Archimedean spaces. Am. Math. Mon. 88, 667-676 (1981)

14. Gordji, ME, Savadkouhi, MB: Stability of cubic and quartic functional equations in non-Archimedean spaces. Acta Appl. Math. 110, 1321-1329 (2010)

15. Gordji, ME, Savadkouhi, MB: Stability of a mixed type cubic-quartic functional equation in non-Archimedean spaces. Appl. Math. Lett. 23, 1198-1202 (2010)

16. Gordji, ME, Khodaei, H, Khodabakhsh, R: General quartic-cubic-quadratic functional equation in non-Archimedean normed spaces. Politehn. Univ. Bucharest Sci. Bull. Ser. A Appl. Math. Phys. 72, 69-84 (2010)

17. Schweizer, B, Sklar, A: Probabilistic Metric Spaces. North Holand, New York (1983)

18. Najati, A, Rassias, ThM: Stability of a mixed functional equation in several variables on Banach modules. Nonlinear Anal. 72, 1755-1767 (2010)

19. Park, C: Fuzzy stability of a functional equation associated with inner product spaces. Fuzzy Sets Syst. 160, 1632-1642 (2009)

20. Gordji, ME, Khodaei, $\mathrm{H}$ : The fixed point method for fuzzy approximation of a functional equation associated with inner product spaces. Discrete Dyn. Nat. Soc. 2010, Article ID 140767 (2010)

21. Adam, M, Czerwik, S: On the stability of the quadratic functional equation in topological spaces. Banach J. Math. Anal. 1, 245-251 (2007)

22. Ebadian, A, Ghobadipour, N, Gordji, ME: A fixed point method for perturbation of bimultipliers and Jordan bimultipliers in $C^{*}$-ternary algebras. J. Math. Phys. 51, Article ID 103508 (2010)

23. Ebadian, A, Najati, A, Gordji, ME: On approximate additive-quartic and quadratic-cubic functional equations in two variables on abelian groups. Results Math. 58, 39-53 (2010)

24. Gordji, ME: Stability of a functional equation deriving from quartic and additive functions. Bull. Korean Math. Soc. 47 , 491-502 (2010) 
25. Gordji, ME: Stability of an additive-quadratic functional equation of two variables in F-spaces. J. Nonlinear Sci. Appl 2, 251-259 (2009)

26. Gordji, ME, Ghaemi, MB, Kaboli Gharetapeh, S, Shams, S, Ebadian, A: On the stability of $\int^{*}$-derivations. J. Geom. Phys. 60, 454-459 (2010)

27. Gordji, ME, Najati, A: Approximately J"-homomorphisms: A fixed point approach. J. Geom. Phys. 60, 809-814 (2010)

28. Gordji, ME, Savadkouhi, MB: On approximate cubic homomorphisms. Adv. Differ. Equ. 2009, Article ID 618463 (2009)

29. Gordji, ME, Ghaemi, MB, Majani, H, Park, C: Generalized Ulam-Hyers stability of Jensen functional equation in Šerstnev PN-spaces. J. Inequal. Appl. 2010, Article ID 868193 (2010)

30. Farokhzad, R, Hosseinioun, SAR: Perturbations of Jordan higher derivations in Banach ternary algebras: An alternative fixed point approach. Int. J. Nonlinear Anal. Appl. 1, 42-53 (2010)

31. Gajda, Z: On stability of additive mappings. Int. J. Math. Math. Sci. 14, 431-434 (1991)

32. Găvruta, P, Găvruta, L: A new method for the generalized Hyers-Ulam-Rassias stability. Int. J. Nonlinear Anal. Appl. 1, 11-18 (2010)

33. Gordji, ME, Kaboli Gharetapeh, S, Park, C, Zolfaghri, S: Stability of an additive-cubic-quartic functional equation. Adv. Differ. Equ. 2009, 395693 (2009)

34. Gordji, ME, Kaboli Gharetapeh, S, Rassias, JM, Zolfaghari, S: Solution and stability of a mixed type additive, quadratic and cubic functional equation. Adv. Differ. Equ. 2009, Article ID 826130 (2009)

35. Gordji, ME, Savadkouhi, MB: Stability of a mixed type cubic and quartic functional equations in random normed spaces. J. Inequal. Appl. 2009, Article ID 527462 (2009)

36. Gordji, ME, Abbaszadeh, S, Park, C: On the stability of generalized mixed type quadratic and quartic functional equation in quasi-Banach spaces. J. Inequal. Appl. 2009, Article ID 153084 (2009)

37. Gordji, ME, Savadkouhi, MB, Park, C: Quadratic-quartic functional equations in RN-spaces. J. Inequal. Appl. 2009 Article ID 868423 (2009)

38. Gordji, ME, Savadkouhi, MB: Approximation of generalized homomorphisms in quasi-Banach algebras. Analele Univ. Ovidius Constata. Math. Series 17, 203-214 (2009)

39. Gordji, ME, Savadkouhi, MB, Bidkham, M: Stability of a mixed type additive and quadratic functional equation in non-Archimedean spaces. J. Comput. Anal. Appl. 12, 454-462 (2010)

40. Adam, M: On the stability of some quadratic functional equation. J. Nonlinear Sci. Appl 4, 50-59 (2011)

41. Kim, GH: Stability of the Lobacevski equation. J. Nonlinear Sci. Appl 4, 11-18 (2011)

42. Khodaei, $\mathrm{H}$, Rassias, ThM: Approximately generalized additive functions in several variables. Int. J. Nonlinear Anal. Appl. 1, 22-41 (2010)

43. Rassias, MJ: J. M. Rassias product-sum stability of an Euler-Lagrange functional equation. J. Nonlinear Sci. Appl. 3 , 265-271 (2010)

44. Mohiuddine, SA: Stability of Jensen functional equation in intuitionistic fuzzy normed spaces. Chaos Solitons Fractals 42, 2989-2996 (2009)

45. Mursaleen, M, Mohiuddine, SA: On stability of a cubic functional equation in intuitionistic fuzzy normed spaces Chaos Solitons Fractals 42, 2997-3005 (2009)

46. Park, C: Generalized Hyers-Ulam-Rassias stability of $n$-sesquilinear-quadratic mappings on Banach modules over $C^{*}$-algebras. J. Comput. Appl. Math. 180, 279-291 (2005)

47. Mohiuddine, SA, Sevli, H: Stability of Pexiderized quadratic functional equation in intuitionistic fuzzy normed spaces. J. Comput. Appl. Math. 235, 2137-2146 (2011)

48. Saadati, $R$, Cho, Y, Vahidi, J: The stability of the quartic functional equation in various spaces. Comput. Math. Appl. 60, 1994-2002 (2010)

49. Park, C: Hyers-Ulam-Rassias stability of homomorphisms in quasi-Banach algebras. Banach J. Math. Anal. 1, 23-32 (2007)

50. Jang, SJ, Park, C, Kenary, HA: Fixed points and fuzzy stability of functional equations related to inner product. J. Nonlinear Anal. Appl. 2012, Article ID jnaa-00109 (2012). doi:10.5899/2012/jnaa-00109

51. Park, C, Rassias, ThM: Isomorphisms in unital $C^{*}$-algebras. Int. J. Nonlinear Anal. Appl. 1, 1-10 (2010)

52. Park, C, Rassias, ThM: Isometric additive mappings in generalized quasi-Banach spaces. Banach J. Math. Anal. 2, 59-69 (2008)

53. Saadati, R, Park, C: Non-Archimedean L-fuzzy normed spaces and stability of functional equations. Comput. Math. Appl. 60, 2488-2496 (2010)

54. Cho, Y, Park, C, Saadati, R: Functional inequalities in non-Archimedean Banach spaces. Appl. Math. Lett. 23(10), 1238-1242 (2010)

55. Park, C, Gordji, ME, Najati, A: Generalized Hyers-Ulam stability of an AQCQ-functional equation in non-Archimedean Banach spaces. J. Nonlinear Sci. Appl. 3(4), 272-281 (2010)

56. Shakeri, S, Saadati, R, Park, C: Stability of the quadratic functional equation in non-Archimedean $\mathcal{L}$-fuzzy normed spaces. Int. J. Nonlinear Anal. Appl. 1, 72-83 (2010)

57. Alsina, C: On the stability of a functional equation arising in probabilistic normed spaces. In: General Inequalities, vol. 5, Oberwolfach, 1986, Birkhäuser, Basel, pp. 263-271. (1987)

58. Mirmostafaee, AK, Moslehian, MS: Fuzzy approximately cubic mappings. Inform. Sci. 178, 3791-3798 (2008)

59. Mirzavaziri, M, Moslehian, MS: A fixed point approach to stability of a quadratic equation. Bull. Braz. Math. Soc. 37, 361-376 (2006)

60. Miheţ, D, Radu, V: On the stability of the additive Cauchy functional equation in random normed spaces. J. Math. Anal. Appl. 343, 567-572 (2008)

61. Miheț, D, Saadati, R, Vaezpour, SM: The stability of the quartic functional equation in random normed spaces. Acta Appl. Math. 110, 797-803 (2010)

62. Miheț, D, Saadati, R, Vaezpour, SM: The stability of an additive functional equation in Menger probabilistic $\varphi$-normed spaces. Math. Slovaca 61(5), 817-826 (2011)

63. Baktash, E, Cho, Y, Jalili, M, Saadati, R, Vaezpour, SM: On the stability of cubic mappings and quadratic mappings in random normed spaces. J. Inequal. Appl. 2008, Article ID 902187 (2008)

64. Najati, A: Fuzzy stability of a generalized quadratic functional equation. Commun. Korean Math. Soc. 25, 405-417 (2010) 
65. Saadati, R, Vaezpour, SM, Cho, Y: A note on the "On the stability of cubic mappings and quadratic mappings in random normed spaces". J. Inequal. Appl. 2009, Article ID 214530 (2009)

66. Deschrijver, G, Kerre, EE: On the relationship between some extensions of fuzzy set theory. Fuzzy Sets Syst. 23, 227-235 (2003)

67. Hadžić, O, Pap, E: Fixed Point Theory in PM-Spaces. Kluwer Academic, Dordrecht (2001)

68. Hadžić, O, Pap, E, Budincević, M: Countable extension of triangular norms and their applications to the fixed point theory in probabilistic metric spaces. Kybernetika 38, 363-381 (2002)

doi:10.1186/1029-242X-2012-168

Cite this article as: Vahidi et al.: A functional equation related to inner product spaces in non-Archimedean $\mathcal{L}$-random normed spaces. Journal of Inequalities and Applications 2012 2012:168.

\section{Submit your manuscript to a SpringerOpen ${ }^{\circ}$ journal and benefit from:}

- Convenient online submission

Rigorous peer review

- Immediate publication on acceptance

- Open access: articles freely available online

- High visibility within the field

- Retaining the copyright to your article 